\title{
Research on Fintech Supervision Model Based on Block Chain Technology
}

\author{
Wei Feng* \\ Department of Economic Management, Fuzhou University Zhicheng College, Fujian, China, 350000 \\ *Corresponding Author email: 170876447@qq.com
}

Keywords: financial science and technology; regulation; block chain technology

\begin{abstract}
Block chaining technology has rapidly become a new global hotspot after the Internet in the field of financial technology (Fintech), attracting close attention from governments, experts and scholars. In practice, the specific meaning of "financial science and technology" is different under different backgrounds, and there are differences and connections with the concept of "Internet finance" in China. Fintech (Financial Technology) is a financial innovation based on artificial intelligence, big data, cloud computing, block chain technology and mobile Internet technology. Financial technology (Fintech) has been developing rapidly because of its obvious advantages in boosting the development of Inclusive Finance. The development of Fintech has played a certain role in the transformation of traditional financial institutions and the innovation of business models. Fintech has promoted the innovation of regulatory mechanism and the innovation of regulatory framework. Financial technology is an innovative activity to transform the mode of production in financial industry by means of science and technology, and thus to improve financial productivity. The development of information technology provides a necessary prerequisite for financial and technological progress. Based on its characteristics of centralization, privacy and programmability, block chain technology has the possibility of innovating the traditional financial payment system theoretically.
\end{abstract}

\section{Introduction}

The concept of block chain was first mentioned in 2008 by Zhong Ben Cong in its paper called "Bitcoin:A Peer-to-Peer Electronic Cash System"[1]. Financial technology is based on a series of technological innovations, such as big data, cloud computing, AI, block chain and so on[2]. Fintech will help to make up for the shortcomings of the traditional financial institutions in promoting the development of Inclusive Finance, and will become an important force in promoting the development of digital Inclusive Finance in the future[3-5]. MelanieSwan (2015), a foreign scholar, divides the development of block chain into three stages, and the era of block chain 1 is the application of encrypted currency[6]. Block chain 2 is the application of contract[7]. The application of block chain technology in financial market is embodied in stock, futures, intelligent assets and intelligent contracts[8]. Block chain 3 will go beyond financial market to a broader field, especially in the fields of science, art and humanities[9]. Technology driven by data and technology is changing the ecological pattern of the financial sector[10]. With the development of mobile Internet, big data, cloud computing, intelligent terminals and other digital technologies.

\section{The Concept of Fintech and Block Chain}

The term "Fin Tech" is the abbreviation of the merger of English Financial Technology. As financial science and technology are still in the early stages of development, the business models involved are still unstable, and there are different levels of different types of business forms, and there is no unified definition in the world at present. From the point of view of China's practice, the development of Fintech has directly promoted the rapid development of China's digital Inclusive Finance. Financial technology has an internal connection with Internet finance, but financial 
technology is a broader concept than Internet finance. At present, Fintech is mainly applied to the following 5 areas: first, the field of market infrastructure, such as digital identity recognition, big data, cloud computing, intelligent contracts, etc. The two is the field of payment and settlement, such as digital money, network and mobile payment, distributed account technology application, etc. The three is financing, such as equity financing, P2P net loan and so on. Four is the insurance sector, such as joint insurance and insurance decomposition. Five, investment management, such as robot investment advisers, electronic transactions, etc.

Because Ethash needs to generate 1G memory space ahead of time in the PoW consensus mechanism, in order to compare the CPU usage that runs steadily, the memory hash value is generated ahead of time. This experiment CPU is a 8 thread, so the Ethernet workshop is set to 8 thread mining method, and the CPU utilization rate is shown in Figure 1.

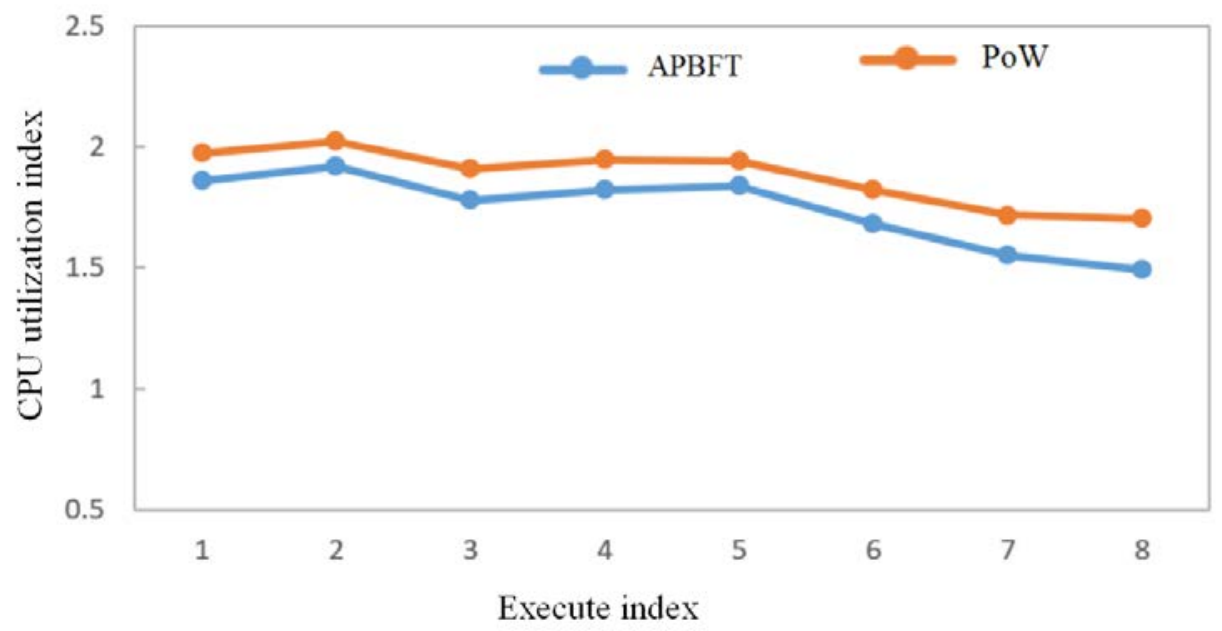

Figure 1 CPU usage rate

Each node in the alliance chain usually has the corresponding entity organization, and can join or withdraw from the network after authorization. The agencies organize a coalition of stakeholders to safeguard the healthy operation of the block chain.

The three types of block chain profiles are shown in Table 1.

Table 1 Block chain classification

\begin{tabular}{|c|c|c|c|}
\hline Content & Public chain & Private chain & Alliance chain \\
\hline Definition & $\begin{array}{l}\text { Anyone can send a } \\
\text { transaction and make } \\
\text { sure that anyone can } \\
\text { participate in the } \\
\text { block chain of } \\
\text { consensus process. }\end{array}$ & $\begin{array}{l}\text { A block chain } \\
\text { controlled by an } \\
\text { organization only by } \\
\text { the write permissions }\end{array}$ & $\begin{array}{l}\text { Under the common } \\
\text { understanding of the } \\
\text { alliance, the block } \\
\text { chain is controlled by } \\
\text { the preselected node. }\end{array}$ \\
\hline Participant & $\begin{array}{l}\text { Anyone is free to go } \\
\text { in and out }\end{array}$ & $\begin{array}{l}\text { Within an individual } \\
\text { or an organization }\end{array}$ & $\begin{array}{l}\text { Specific population, } \\
\text { union agreement }\end{array}$ \\
\hline Trust mechanism & Proof of work & Self endorsement & $\begin{array}{l}\text { Collectives } \\
\text { endorsement }\end{array}$ \\
\hline $\begin{array}{l}\text { excitation } \\
\text { mechanism }\end{array}$ & Need & Unwanted & Optional \\
\hline $\begin{array}{c}\text { Degree of } \\
\text { centralization }\end{array}$ & Centralization & Centralization & Multi centralization \\
\hline Protruding advantage & $\begin{array}{l}\text { Self establishment of } \\
\text { trust }\end{array}$ & $\begin{array}{l}\text { Transparent and } \\
\text { traceable }\end{array}$ & $\begin{array}{l}\text { High efficiency and } \\
\text { cost optimization }\end{array}$ \\
\hline $\begin{array}{l}\text { Representative } \\
\text { organization }\end{array}$ & Bitcoin, ether square & DDT audit & R3 bank Alliance \\
\hline
\end{tabular}

Block chain is an important concept of bitcoin, and is the underlying technology and infrastructure 
of bitcoin. "Financial technology" has both connections and differences with the concept of "Internet finance" in China. Internet finance is also a part of financial science and technology. Internet finance uses financial science and technology to innovate, and financial science and technology enterprises will use the Internet channel to carry out business. Block chain technology has broad application space and development prospects in the financial field. For example, in the field of payment and liquidation, block chain technology is the first innovation. The Ripple system based on block chain technology can realize the function of de Centralization Payment and liquidation, and has been introduced by many banking institutions in the cross-border business in the UK. Financial technology is more general and more inclined to technology. The financial industry as an information intensive industry, every innovation and large-scale application of information technology has profoundly changed the face of the financial industry. Financial technology focuses more on the application and popularization of new information technology, such as big data, cloud computing, block chain, artificial intelligence and mobile Internet. And emphasize their important role in enhancing financial efficiency and optimizing financial services.

The total utility level of consumers in their life cycle is the sum of utility levels in each period. In order to ensure that the model is closer to reality, discount factor is introduced here. The $X_{i}$ in the upper form is the consumer's consumption in the i period. Therefore, the total utility level of consumers can be expressed as follows:

$$
\begin{aligned}
& X_{i}=\left(X_{i 1}, X_{i 2}, X_{i 3}, \ldots, X_{i d}\right)^{T} \\
& X_{i d} \in\left(X_{\text {min }}, X_{\text {max }}\right)
\end{aligned}
$$

T represents the consumer's life cycle, and $X_{\operatorname{man}}$ is the psychological discount rate.

$$
\begin{aligned}
& V_{i}=\left(V_{i 1}, V_{i 2}, V_{i 3}, \ldots, V_{i d}\right)^{T} \\
& V_{i d} \in\left(V_{\text {min }}, V_{\text {max }}\right)
\end{aligned}
$$

The $V_{i}$ in the upper form is the consumer's income in the i period. $V_{i 1}$ indicates the knowledge and technology that consumers invest in i1. $V_{i 2}$ indicates that the work done by consumers during the i2 period indicates that the multiplier of work efficiency, $V_{\min }$ and $V_{\max }$ are the multipliers of capital and labor respectively.

$$
P_{i}=\left(P_{i 1}, P_{i 2}, P_{i 3}, \ldots, P_{i d}\right)^{T}
$$

$P_{i}$ is the market discount rate and $\mathrm{T}$ is the time for consumers to retire.

The objective of rational consumers is to maximize the level of utility in life. The utility level of the consumer is related to the amount of consumption. The level of the consumer's wealth is related to the capital and labor of the consumer.

$$
P_{g}=\left(P_{g 1}, P_{g 2}, P_{g 3}, \ldots, P_{g d}\right)^{T}
$$

$V_{\text {id }}$ free, c1 and r1 have been identified. The maximum value is:

$$
V_{i d}=w V_{i d}+c_{1} r_{1}\left(P_{i d}-X_{i d}\right)+c_{2} r_{2}\left(P_{g d}-X_{i d}\right)
$$

The best strategy for the $V_{\text {id }}$ consumer in the upper form is to consume all the wealth in the whole life cycle, because the surplus of wealth does not raise any utility level for the consumer.

The PBFT mechanism and the improved PBFT mechanism are used to test it. In the process of a complete deletion of the certificate, the test results of the transfer network overhead of the certificate are shown in Figure 2. Figure 3 shows the network overhead in the process of a complete view switch when the main node fails. 


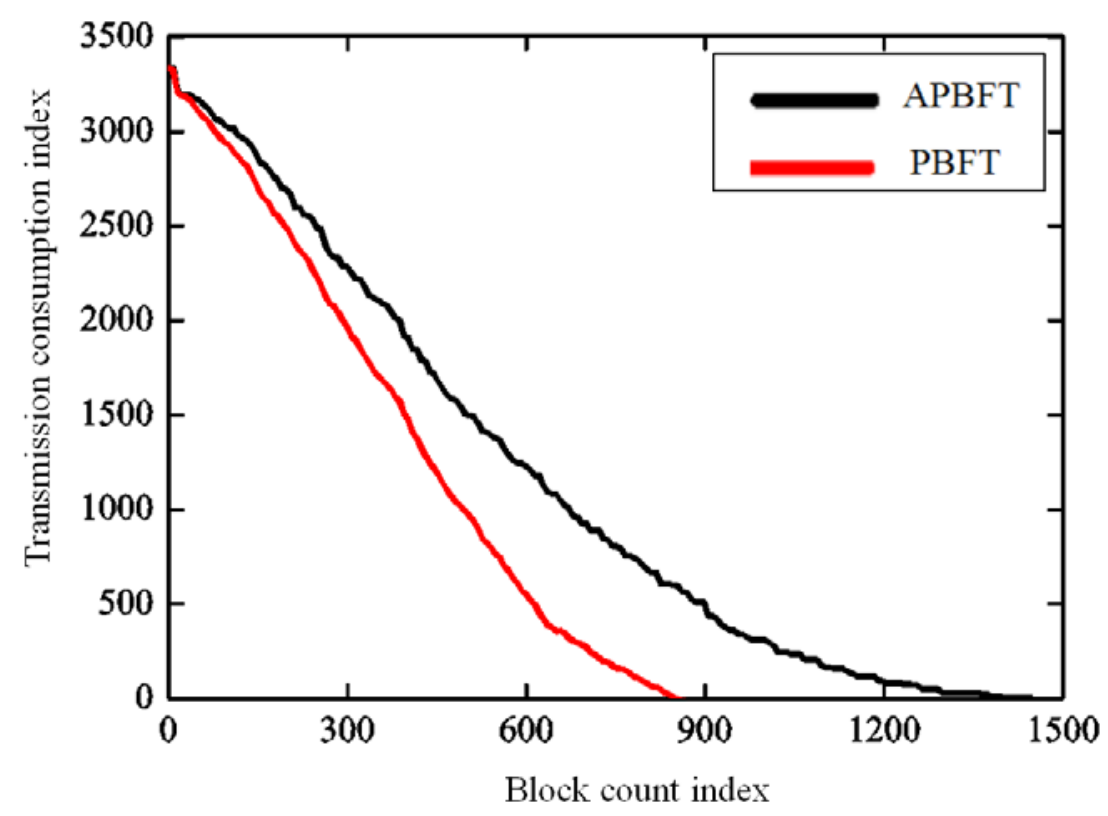

Figure 2 Certificate transmission overhead

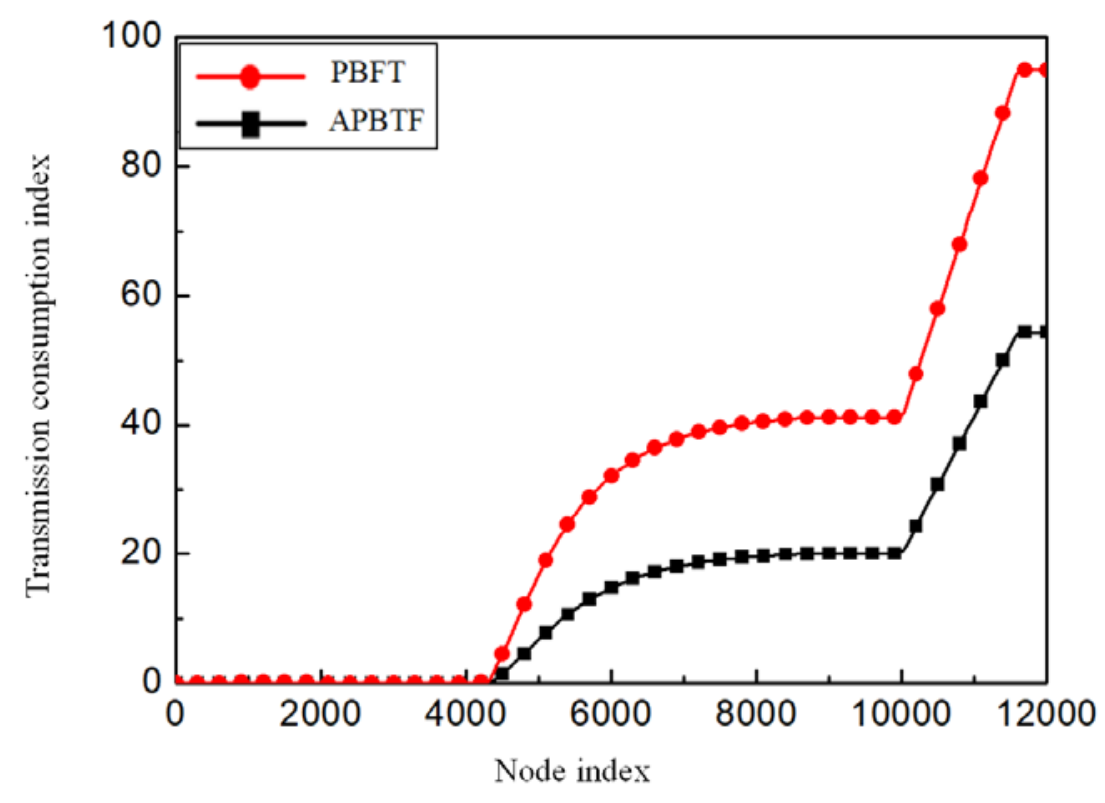

Figure 3 View switching transmission consumption

\section{The Main Practice of Financial Science and Technology Supervision in China}

China's huge market demand and the financial service system to be improved have made the application of financial technology more and more widely developed. In recent years, a special working group has been set up by the financial stability Council, the Basel Banking Regulatory Commission, the International Securities Regulatory Commission and the international insurance supervision Association. From different angles, we study the development and evolution of financial science and technology, the change of the risk, the impact on the financial system and the regulatory response, and explore how to improve the regulatory rules and improve the mode of supervision. With the continuous development of Fintech, countries are constantly exploring their regulatory tools and innovating the regulatory framework. Previously, there were three main modes of international regulation of Fintech. They are the restrictive regulation represented by the United States, the passive regulation with China as the representative, and the active supervision by the United Kingdom. Scientific and technological innovation gradually affects the financial industry, which has a profound 
impact on the traditional financial industry in the aspects of operating speed, operating cost, business data, media and so on.

Because the Json-RPC interface is only provided in the Ethernet workshop, it is necessary to write the Web Service interface to the Ethernet workshop to realize the interaction process with the Web server. The interface management information is shown in Table 2.

Table 2 Block chain management interface information

\begin{tabular}{|c|c|}
\hline Name & Parameters and instructions \\
\hline Account Info & $\begin{array}{c}\text { The parameter is the account address. It is used to query account } \\
\text { information. }\end{array}$ \\
\hline Block Num & It is used to query the number of blocks in the current block chain. \\
\hline Block Info & $\begin{array}{c}\text { The parameter is the block number. Information that is used to query } \\
\text { blocks. }\end{array}$ \\
\hline Active Node & Returns the reliable node considered by the current node. \\
\hline Balance & $\begin{array}{l}\text { The parameter is the account address. Return the balance of the } \\
\text { account. }\end{array}$ \\
\hline $\begin{array}{l}\text { Batch } \\
\text { Transactions }\end{array}$ & $\begin{array}{l}\text { The parameter is the account address and the corresponding account } \\
\text { amount. It is used to initialize the account amount for the system. }\end{array}$ \\
\hline Batch Accounts & $\begin{array}{l}\text { The parameter is the account address. It is used to initialize the } \\
\text { account. }\end{array}$ \\
\hline
\end{tabular}

China's supervision of financial technology still relies on the existing laws and regulations, and its flexibility and timeliness are relatively insufficient. At present, China's separate supervision of financial technology is still in the initial stage of exploration, mainly following or adaptive supervision. The issue and transaction of the block chain technology can turn the point to point transaction into reality, and the broker and agent will no longer exist, and the securities in the form of digital form will replace the physical securities in an all-round way. The regulatory framework adapts to the development of Fintech in the process of continuous exploration and innovation, and eventually makes the three models converge to the active adaptive regulatory model. With the maturity of AI technology and block chain technology, financial technology is spreading to a wider field. Financial technology has built a solid foundation of financial technology and a powerful platform which can be used conveniently. It greatly reduces the cost and difficulty of financial innovation, and greatly expands the imagination space and covering fields of financial innovation.

Auditors usually check "bank inquiry and check the register book" to track the main whereabouts of bill discount funds, inquire the transaction flow of the account and extend the related enterprises. As shown in Table 3.

Table 3 The amount of the electricity ticket and the proportion in the commercial bill of exchange

\begin{tabular}{ccccc}
\hline $\begin{array}{c}\text { Particular } \\
\text { year }\end{array}$ & $\begin{array}{c}\text { Check } \\
\text { settlement } \\
\text { amount }\end{array}$ & $\begin{array}{c}\text { Amount of } \\
\text { ticket out of } \\
\text { ticket }\end{array}$ & $\begin{array}{c}\text { Total amount } \\
\text { of paper ticket }\end{array}$ & $\begin{array}{c}\text { Ratio of } \\
\text { electric } \\
\text { meter(\%) }\end{array}$ \\
\hline 2014 & 20.2562 & 1.2566 & 12.2654 & 9.00 \\
2015 & 23.0265 & 2.2665 & 10.2321 & 12.32 \\
2016 & 21.0254 & 1.2351 & 11.1255 & 21.26 \\
2017 & 25.6542 & 6.3264 & 15.3454 & 30.23 \\
\hline
\end{tabular}

\section{Conclusion}

The financial industry has undergone many technological innovations in the past, but so far it has not been fundamentally and subversive. The transaction system based on block chain will enable the financial institutions to share the transaction information on the block chain, ensure the traceability of the data, and enhance the strength of anti money laundering. Financial technology will become a 
necessity for people's life in the future. Financial science and technology and industry, agriculture and other industries are deeply linked, such industries as assets management, capital operation, investment returns and many other aspects of great changes will take place. The regulatory authorities should actively respond to and accept the change of block chain technology to the regulatory mode and keep pace with the times. It is necessary to improve supervision methods and improve the efficiency and quality of management based on block chain and other new financial technology. China's block chain industry has also begun to develop continuously.

\section{References}

[1] Chen P W, Jiang B S, Wang C H. Blockchain-based payment collection supervision system using pervasive Bitcoin digital wallet[C]// Wireless and Mobile Computing, NETWORKING and Communications. IEEE, 2017:139-146.

[2] PoWei Chen, BoSian Jiang, ChiaHui Wang. Blockchain-based payment collection supervision system using pervasive Bitcoin digital wallet [J]. Medical Device Daily, 2017, 34(1):25-28.

[3] Zavolokina L, Dolata M, Schwabe G. FinTech Transformation: How IT-Enabled Innovations Shape the Financial Sector[C]// International Workshop on Enterprise Applications and Services in the Finance Industry. Springer International Publishing, 2016:75-88.

[4] Eyal I. Blockchain Technology: Transforming Libertarian Cryptocurrency Dreams to Finance and Banking Realities [J]. Computer, 2017, 50(9):38-49.

[5] TSAI Chang-hsien, PENG Kuan-Jung. The FinTech Revolution and Financial Regulation: The Case of Online Supply-Chain Financing [J]. Asian Journal of Law and Society, 2017, 4(1):109-132.

[6] Fan P S. Chapter 15 - Singapore Approach to Develop and Regulate FinTech[J]. Handbook of Blockchain Digital Finance \& Inclusion, 2018:347-357.

[7] Tan C Y, Schulte P, Chuen D L K. Chapter 11 - InsurTech and FinTech: Banking and Insurance Enablement [J]. Handbook of Blockchain Digital Finance \& Inclusion, 2018:249-281.

[8] Salampasis D, Mention A L. Chapter 18 - FinTech: Harnessing Innovation for Financial Inclusion [J]. Handbook of Blockchain Digital Finance \& Inclusion, 2018:451-461.

[9] Nakashima H, Aoyama M. An Automation Method of SLA Contract of Web APIs and Its Platform Based on Blockchain Concept[C]// IEEE International Conference on Cognitive Computing. IEEE, 2017:32-39.

[10] Kursh S, Schnure A. Fintech and blockchain for senior IT managers [J]. Cutter It Journal, 2016, 29(11):12-17. 